\title{
PREPARING LEARNERS FOR A GLOBAL EXPERIENCE: AN ANALYSIS OF INTERCULTURAL CONTENTS IN GOVERNMENT SCHOOL EFL TEXTBOOKS IN PAKISTAN
}

\author{
Imdad Ullah Khan ${ }^{1 *}$, Rafique Ahmed Memon ${ }^{2}$, Mansoor Khan ${ }^{3}$, Sidra Amina ${ }^{4}$, Saood Khan ${ }^{5}$ \\ ${ }^{1 *}$ Assistant Professor, Department of English, University of Swat, Khyber Pakhtunkhwa, Pakistan; ${ }^{2}$ Professor, Institute \\ of English Language and Literature, University of Sindh Jamshoro, Pakistan; ${ }^{3}$ Lecturer, KUST, Khyber Pakhtunkhwa, \\ Pakistan; ${ }^{4}$ University of Lahore, Punjab, Pakistan; ${ }^{5}$ University of Swat, Khyber Pakhtunkhwa, Pakistan. \\ Email: ${ }^{1 *}$ Imdad.Khan@ @uswat.edu.pk, ${ }^{2}$ rafique.memon@usindh.edu.pk, ${ }^{3}$ sparlay2018@gmail.com, \\ ${ }^{4}$ sidraAmina786@gmail.com, ${ }^{5}$ sauoodkhan896@gmail.com
} Article History: Received on $22^{\text {nd }}$ May 2021, Revised on $30^{\text {th }}$ May 2021, Published on $6^{\text {th }}$ June 2021

\begin{abstract}
Purpose of the study: This study aims to build the capacity of a learner as a "global citizen," language teaching needs to focus on building the $5 \mathrm{C}$ 's of Communication, Cultures, Connections, Comparisons, and Communities along with language proficiency. The present study analyzes English language textbook contents taught at the secondary school level in Pakistan's postcolonial and multilingual context.
\end{abstract}

Methodology: Identity and otherization are used as key heuristic tools to analyze the ideological texture of the focal texts and their influence on adolescent learners' emerging identities.

Main Findings: Data analysis in the current article shows that texts in the textbook promote strong in-group identities. Exercises and activities for students focus on lexico-syntactical aspects of the texts. The communicative and intercultural skills of the students are not stimulated in the textbook.

Applications of this study: This study can be useful for improving English language textbooks, and classrooms need to move beyond traditional language teaching and incorporate active critical thinking and intercultural awareness to suit the needs of the students in the globalized world of our present times.

Novelty/Originality of this study: To create a more stable world in this age of interconnectedness, mobility, and globalization, our young generation needs to develop fluid identities open to dialogue with the Other and seek complexity instead of simplification and stereotyping in intercultural encounters.

Keywords: Intercultural Awareness, Intercultural Communicative Competence, Identity, Otherization, Culture, Globalization.

\section{INTRODUCTION}

Language is an integral part of a culture, and as such, the relevance of culture in the teaching of language can hardly be exaggerated (Darvin \& Norton, 2015). According to Khan et al. (2021a), language is functional only concerning the context in which it is employed. Language, therefore, functions as a point of reference to something beyond it, that is the cultural context. During the last few decades, the importance of developing Intercultural Communicative Competence (ICC) of the language learners received more significant attention (Khan et al., 2021b).

In today's globalized reality, intercultural teaching of foreign languages has become more relevant as people frequently interact through technology and move across borders more often for reasons ranging from business to education and immigration to seeking asylum. However, teaching and learning of culture is a diverse multidisciplinary field that is a point of convergence for various disciplines, including social psychology, anthropology, linguistics, education, politics, etc. (Mahboob, 2015).

To build a learner's capacity as a "global citizen," language teaching needs to focus on building other skills along with language proficiency. According to Islam \& Asadullah (2018), developing the learners' language skills lies "at the heart of language studies." Still, the purpose of language teaching and learning must also encompass the 5 C's of Communication, Cultures, Connections, Comparisons, and Communities if the learner is to develop ICC and participate meaningfully in culturally diverse experiences in the modern interconnected world. Similarly, Ahmad \& Shah (2019) point out that language instruction is designed to prepare learners for meaningful and productive interaction with other cultures and "asks students to think and act appropriately within a growing knowledge of the culture within language." Therefore, this approach to language teaching necessitates instructional planning, which allows time and space for the teacher and learner to explore concepts of cultural empathy, discovery, and exploration. It is, therefore, imperative to develop ICC in a foreign language learner through a curriculum that incorporates best practices in culture-sensitive teaching and learning (Setyono \& Widodo, 2019).

The current article focuses on textual analysis of textbook material in a northern part of Pakistan. Textbooks are an essential instrument of socialization of students into citizens with specific identities and play a vital role in a government's planning. Using discourse analysis and sociolinguistic perspective, the article first outlines the main themes discussed in the fields of intercultural awareness and ICC. Next, textual data from the Class 10 textbook is 
analyzed in terms of identity construction and otherization to understand how learners are socialized into certain kinds of citizens and how it may affect their ability to engage in online or physical intercultural communication. Specifically, the article attempts to find answers to the following questions:

1. How textual construction of students' identity inform notions of in-group and out-group perceptions of the Self in the focal texts?

2. How texts represent the Other, and what role may otherization play in informing students' perception of the Self and their trajectories of intercultural competence?

3. What are the implications of the current study for developing secondary school students' intercultural competence in Pakistan?

\section{REVIEW OF LITERATURE}

\section{English Language Teaching In Pakistan}

In Pakistan, language teaching is focused more upon developing the linguistic knowledge of the learner rather than acquiring language skills through the development of the ICC of the students. In her study of 21 public sector universities in different provinces of Pakistan, Setyono \& Widodo (2019) found that teaching English at the undergraduate level suffers from severe drawbacks, including lack of formal training of teachers in the teaching of English as a foreign language to adult learners; reluctance of teachers to use educational technology in the classroom even when it is available. In addition, the study pointed out a lack of participatory learning in the classroom and resulting lack of communicative competence among learners. As a result, English language teaching practices fail to prepare students to participate in global culture. At the same time, the young generation in Pakistan is eager to be part of the global community through developing their English language skills (Setyono \& Widodo, 2019).

In Pakistan, English language skills are tied up with social class and educational and family background. Manzoor et al. (2019) claim a state of "language apartheid" in the education system exists in Pakistan. Children of well-off parents attend more costly English Medium schools while the rest attend government-run Urdu medium schools. English language proficiency thus developed due to early years of schooling gives the children of well-off families a significant advantage over the others. They can excel relatively easily at the tertiary level compared to students who study in Urdu medium schools (Joo et al., 2020). Therefore, the teaching of English in Pakistan is laden with social implications that pose challenges to language planners, policymakers, and practitioners. However, these challenges are not unique to Pakistan. Many African and Asian countries face similar issues about achieving quality in the teaching of English as a foreign language and striking a balance between demand for local languages and the need for English to participate in global culture (Setyono \& Widodo, 2019).

\section{Language, Culture, and Politics in Pakistan}

In the postcolonial, multiethnic, and multilingual national context of Pakistan, language teaching and planning is inextricably connected with politics of language, state governance, distribution of power, and promotion of local cultures. The advancement of languages and their planning and teaching remain favorite topics in the political discourse and at the center of a heated national debate (Setyono, 2018). In Pakistan, English is the official language of the state, while Urdu is the national language. There are at least five major local languages, including Punjabi, Pashto, Sindhi, Siraiki, \& Balochi (Arshad et al., 2020), competing for supremacy in this diverse national context. Similarly, like most of the other developing countries, "English as the language for development" and "English as the passport to success and upward social mobility" (Setyono, 2018) are recurrent themes in the political and scholarly discourses in Pakistan. In addition, the realization of English as the language of demand in the global market has gained currency in the language discourse in Pakistan, which has added another policy dimension to the already complex issue of language planning in the country (Deswila et al., 2021).

Demand for the English language exists in all strata of the society in Pakistan, ranging from elite private educational institutions to public sector schools, colleges, and universities (Ariawan, 2020). Thus, it is not just the government pushing English as the language of promise for international communication. Still, the public is also pulling it as they realize that it is the language of access to domains of power and a potential means of changing their social class (Peng, 2020). In his survey of student's attitude towards the English language, Rahman found that the desire for learning English occurs consistently not only in all types of schools in the country, representing different social layers of the society, but English is also sought after by the students of madrassah (religious non-government schools) who subscribe to the most conservative stance in Pakistani society (Ali et al., 2021). Similarly, in her case study of language planning in higher education in Pakistan, Setyono (2018) found that an overwhelming demand for the English language exists among students throughout Pakistan. Instead of being viewed as a vestige of the colonial rule, which is associated with political hegemony and appropriation of indigenous culture by a foreign nation, English is now accepted in Pakistan as an essential tool for individual prosperity and a key to open up new possibilities of getting access to positions of power in the country. 
In Pakistan, a significant need for the English language exists due to its promise of gaining personal prosperity, access to positions of power, and participation in global cultures. However, the current need for the English language far exceeds the provisions made for teaching-learning of English in educational institutions. English is a compulsory subject in schools and colleges in the country, but it is not a de facto medium of instruction in government schools and low-fee private schools. At the university level, English is the medium of instruction for almost all courses. However, despite a national preference for it, the English language proficiency of the learners at all levels remains primarily poor. Studies suggest that educational policy adopted by successive governments failed to do a proper analysis of the problems faced by learners and teachers, and there was seldom any debate and consultation with scholars and linguists regarding the best possible solutions and the procedure for implementation of a language policy (Mukhtar et al., 2021).

Intercultural language models indicate that language learning is not about acquiring language skills by gaining knowledge about morphology, syntax, phonology, and vocabulary of the target language. Instead, to learn a new language and develop ICC, the learner must acquire cultural knowledge and awareness of the target language's culture and other global cultures (Gholaminejad \& Raeisi-Vanani, 2021). However, in Pakistan, teaching interculturality through language and culture in foreign language classrooms remains neglected. The following section reviews significant models of interculturality and some key constructs used to incorporate interculturality into foreign language teaching.

\section{Intercultural Competence}

A concise definition of Intercultural Competence (IC) may not be possible given the complexity of the idea and its multidimensional nature. However, research points towards two recurrent themes as fundamental for developing IC self-awareness and identity transformation (Dinh \& Siregar, 2021). The complexity of culture and IC poses a challenge for the language classroom because the idea of IC can be defined in various forms in different teaching contexts. For example, Zhang (2021) defines culture as a complex and ever-changing phenomenon that makes it difficult to decide which aspects to incorporate in the language classroom. Khan et al. (2021) think of culture as an "elusive and multilayered notion [which] defies easy categorization and classification." Furthermore, in the modern era of global technology and ever-increasing intercultural contacts, the objectives of IC in the language classroom continuously evolve and change at a fast rate (Amin, 2021).

Models of IC deal with self-awareness and internal transformation from different perspectives as fundamental components. In his Developmental Model of Intercultural Sensitivity (DMIS), Dinh \& Siregar (2021) charts the development from "ethnocentrism" to "ethnorelativism" in the context of intercultural communication. According to Aziz et al. (2020), for effective ICC, the learner must make a successful transition from a worldview of avoiding cultural difference to seeking cultural difference. Baig et al. (2020) Anxiety/Uncertainty Management (AUM) model places anxiety management at the center of ICC and stresses that high anxiety in intercultural situations leads to misinterpretation and lack of ability to interpret cultural clues accurately. He emphasizes that to develop the ability to deal with new cultural situations, one must learn to manage anxiety in new cultural environments (Amin, 2021). In his Multidimensional Model of Intercultural Competence, Asif et al. (2020) propose that developing the right attitude is the key element an individual must have to develop IC. He draws attention to openness and curiosity as fundamental characteristics of an individual who can learn about new values, traditions, beliefs, and worldviews to participate in relationships of equality. For Abe (2020), it is a good practice if the students record their preconceptions regarding the foreign culture before embarking on discovery in the class. It will provide them with a reference for comparison once they have completed learning about the foreign culture.

Apart from these models, several scholars have also stressed the importance of self-awareness and internal transformation as the starting points for achieving the goal of IC. For example, in her study conducted to elicit the opinion of university administration and intercultural scholars regarding the elements of IC, Mukhtar et al. (2021) found that both groups considered self-awareness and being accommodative of new values and beliefs as the key to developing an attitude for IC. Similarly, it is also crucial that the environment of the foreign language classroom should be conducive to making such transformation possible. The environment in an intercultural classroom is described as participatory, cooperative, learner-centered, and engaging (Osman, 2015). In an ideal intercultural classroom, the student is somewhat like an anthropologist who explores and investigates other cultures and reflects upon the comparative characteristics of his/her own culture (Sarmiento et al., 2020). In this environment, students move at a different pace from one another. Therefore, their progress should be viewed not as a goal to be achieved but a process in which they participate and reach individual milestones of success in interculturality (Salem, 2019). In her Process Model of Intercultural Competence, Hacker \& Umpstead (2020) envisages interculturality as a circular one that allows individuals to enter into the process at different points. Sometimes they move forward in their journey of ICC, while at other times, they come back to reconsider a point previously encountered in the class.

\section{Intercultural Communicative Competence}

According to Darvin \& Norton (2015), someone who develops intercultural communicative competence (ICC) is successful in establishing relationships in a foreign language of the other participants; can conduct conversations in a situation involving culturally diverse participants, and can continue to acquire communicative skills in foreign languages not yet studied. However, ICC is more than the ability to exchange ideas in a foreign language successfully. It is about 
building a relationship of reciprocity with the other interlocutors even when the speaker involved do not share the same worldview (Khan et al., 2021a).

In Khan et al. (2021b), the teacher guides learners through activities designed to sensitize them to any preconceptions about the Other. Ideally, the learners will eventually be transformed into individuals willing to find out and engage with otherness and progress towards developing relationships of reciprocity. It is also essential that the teacher allows the learners to explore their indigenous culture and the target culture from religious, historical, geographical, and social perspectives. Once this has been accomplished, the teacher will design activities to prepare learners to build relationships with people from diverse cultural backgrounds. Next, learners must be given time and guidance to interpret cultural phenomena in the light of ethnocentric worldviews and the resulting misunderstandings in cross-cultural scenarios. The next phase should enable learners to pinpoint the ethnocentric origin of conflict in intercultural situations. As a result, the learner may now have the capacity to mediate situations successfully and avoid misunderstandings, potentially leading to conflict. Furthermore, in the interactive, learner-centered environment of the intercultural foreign language classroom, teachers and students consider questions of values and morals that promote democratic norms $\underline{(\text { Mahboob, 2015). }}$.

In the light of Islam \& Asadullah (2018), traditional approaches to the teaching of English as a Foreign Language (EFL) need to be transformed because they often view students' language proficiency as primarily a matter of acquisition of a lexico-grammatical system based on a standardized form of that language. Instead, language teachers could facilitate an environment in the language classroom where learners evaluate and critique the concepts of Self and Other and reflect upon their perception, beliefs, and responses to perceived others while acquiring a new language, a new semiotic system. This approach to teaching English as a foreign language can produce global citizens who are interculturally competent and can engage in a dialogue of reciprocity with participants from other cultures.

\section{METHODOLOGY}

Interculturality has been studied with the help of different models that attempt to capture culture in action in verbal or textual interaction (Flores et al., 2015). The current study uses a model of interculturality developed by Jackson (2021). Although the authors do not put forward explicitly the following framework as a model of interculturality, the textual data analyzed in this article can be usefully lensed through this model to assess whether and how the textbook contents studied in this article develop students' intercultural competence. The model includes three essential aspects of assessing interculturality, namely identity, otherization, and representation. Due to space limitations, the following analysis operationalizes only the first two of these analytical constructs - identity and otherization.

Identity indexes how individuals see themselves, how they identify with certain groups and not others, and how these notions of Self and Other determine their future trajectories. Identity is not a static central core but a work in progress mediated by the sociocultural context and the discourses available in this context. Like other individuals, students' identity is socioculturally situated, changes within social domains and across time, and is mediated by ideologies (Asadi \& Sasani, 2017). Intercultural competence is contingent upon whether or not we build a solid in-group identity and seek a deeper understanding of how others project/present themselves. Strong and static in-group identity is not conducive for intercultural contact situations. It is essential to avoid preconceptions and appreciate the complexity of other people's cultural orientation (Pérez Gracia, 2016).

Otherization refers to how one perceives an Other as an Other. The way we negotiate similarity and difference in intercultural interactions is connected with our perception of who is included in our in-group identity and who is part of the out-group identity. In intercultural contact situations, one is in danger of perceiving exotic (different, novel) ideas, norms, and artifacts as evidence of stereotypical similarity between whole groups based on nationality, religion, gender, etc. To counter this tendency, it is essential to seek a deeper and more complex understanding of the prejudices, preconceptions, and discourses that lead you to otherize (Riebeling, 2018). Both in textual or interactional instances, discourses and ideologies underpinning them can challenge or reinforce otherization by encouraging overgeneralization, exotification, and stereotyping. The third construct of representation refers to how the foreign Other is represented and how socially dominant textual and non-textual discourses perpetuate particular representations. Through channels of distribution like media, textbooks, newspapers, etc., representation can marginalize groups of people based on foreignness, ethnicity, religion, color, or gender leading to fractured social structure and inequity.

In the following analysis, we build on this model of interculturality to explain in sociolinguistic terms how textual construction of students' identity informs notions of in-group and out-group perceptions of the Self and how otherization plays a role in informing students' present and future trajectories of intercultural competence. The nexus between identity, otherization, and textual language is analyzed at the two levels of content and language.

\section{RESULTS/FINDINGS/ANALYSIS}

This section analyzes texts from the Class 10 textbook taught in the Khyber Pakhtunkhwa province of Pakistan. The analysis is structured by two analytical constructs identified in a model of interculturality in the methodology section, namely identity, and otherization. These analytical constructs are used to assess the focal texts at two levels, i.e., at the content and linguistic levels. The analysis aims to assess the relevance of the texts for preparing students for intercultural 
encounters and communication in international contexts. At the beginning of the textbook, Editor's introduction to the textbook states:

Revision of the current edition was undertaken to align the textbook with the standards for textbooks included in the Minimum National Standards for Quality Education in Pakistan...in content, organization, presentation, layout, assessment, cultural values, and elimination of all forms of biases. [It includes] essays, stories, poems...factual accounts, environment, fantasy, adventure, fables, and poetry. (p. 1)

The introduction further states that the texts and exercises aim to develop students' ability to understand context through a variety of reading genres; learn reading comprehension, grammar, composition, listening, and speaking skills. The introduction, however, does not include any specific policy statement or teaching strategy for developing students' intercultural understanding and enabling them to effectively engage in intercultural communication. The following sections analyze texts to see whether intercultural aspects are incorporated into the texts and what type of activities students are asked to undertake at the end of each text.

\section{Identity}

Textbooks are powerful tools in shaping the present and future identities of the students because schools legitimize certain forms of knowledge and meanings as more authentic than others (McDonough, 2018). What students read and see in the textbooks has long-term effects on how they perceive themselves as individuals and as members of ethnic, religious, or national groups. This section focuses on aspects of nationalistic and cultural identity construction in the text titled "Iqbal's Message to Youth" (pp. 12-23). Like all texts in this book, the theme of the text is stated as "patriotism" before students have read it, engaged with the content, and expressed their evaluation of what might be its theme. We analyze the organization of the text in terms of "rhetorical moves" (Tong, 2020) employed to achieve organize the text and construct a specific identity for the students to aspire to. Secondly, we analyze how the text constructs nationalistic identity through a subtle construction of "unicity" build on the conception of a coherent national core. The implications of these aspects of the text are significant for intercultural awareness and ICC.

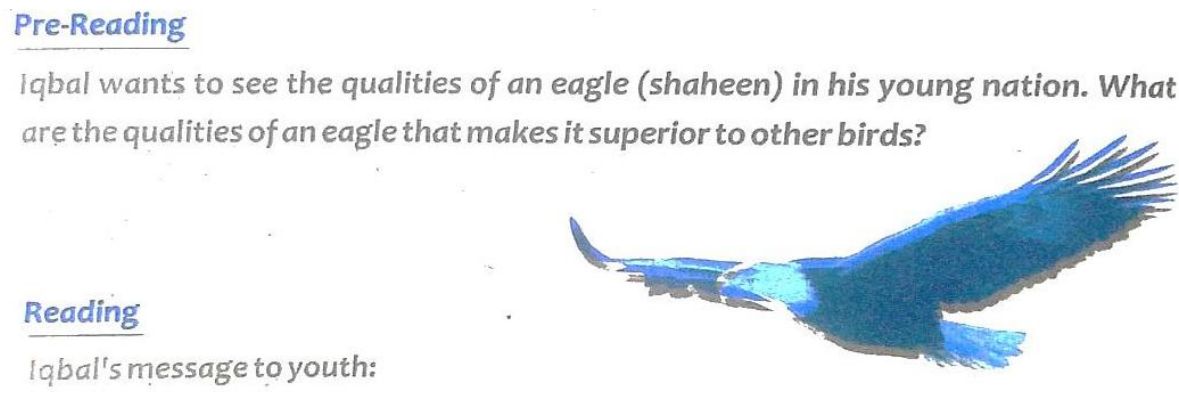

Figure 1: Brainstorming activity for students

First, the text establishes grounds for the superiority of Iqbal's message who was a key figure in the liberation struggle of Indian nations against British colonial occupation that culminated in the creation of India and Pakistan in 1947. Iqbal's poetry is a vehicle for his philosophy of individuation (khudi), power, and struggle (inner and outer) as a panacea for Muslims in the Indian subcontinent to liberate themselves. At the beginning of the text, multimodal semiotic resources are employed to nudge the students in the direction of the message that the text explicitly states afterward in the text (Mesaros, 2016). The multimodal resource consists of the image of an eagle and the accompanying text asks students to enumerate qualities that make an eagle distinct and superior to other birds (Figure, 1). The themes of being distinct from others and committing oneself to a perpetual struggle run throughout the lesson. The text quotes Iqbal as saying, "Know thyself and success shall be thine".

In the present age of globalization, identity is seen as fluid, emergent, and socioculturally contingent. It is constructed in interactions, including interacting with texts (Khan et al., 2021b). To prepare learners for a future where they might have diverse intercultural encounters, it is necessary for schooling to adopt a dialogic mode of learning. Through dialogic engagement with texts, students develop capacities for peaceful negotiation of difference, seeking complexity, and avoiding pitfalls of projecting previous experiences onto the present to stereotype the Other. All of these capacities are underpinned by the use of critical thinking in education and textbooks that encourage this. The focal text, however, employs successive rhetorical moves to establish its message of a distinct and superior identity for Iqbal's ideal youth. It does not invite the reader to critically engage with the claims made in the text but ascribes and projects Iqbal's youth as seeking perpetual struggle, being energetic, mild in speech but enthusiastic in action (Holmes, 2015). Whereas in an earlier rhetorical move the text establishes an ideal youth as having achieved individuation (self-knowledge, khudi), in a later rhetorical move Iqbal's youth is "not a thinking Hamlet but a man of action" (p. 15). This ambivalence between whether to stress the acquisition of self-knowledge or outward power as a more desirable trait of Iqbal's youth sends contradictory messages to the students. The text ends with proclaiming "unicity" 
It can be concluded that youth was the main focus of Iqbal. He declared youth as a symbol of hope and the future of the nation. If the young generation is ready to contribute to the progress and prosperity of the Ummah (global Muslim collective), the day is not far off when the whole Muslim community will rise as mighty power which no nation of the world will be able to subdue. (p. 15)

Although the text concludes with an optimistic note for the Pakistani/Muslim youth who are assigned the responsibility to make Ummah a mighty power, the "unicity" and assertiveness of Muslim youth identity created in the text sits uncomfortably with the present era of globalization.

Exercise activities based on the text includes comprehension-based questions asking students to reproduce specific parts of the text, discrete grammar (pronouns), and vocabulary building. The exercise however does not invite students to engage critically with the text and their social lives. In listening and speaking activities, the students are asked to "recite a poem of Iqbal in front of the class" and "discuss in groups Iqbal as the dreamer of Pakistan" (p. 20). In the writing activity, students look at a mind map (Figure, 2) and write a paragraph about "youth from Iqbal's perspective" (p. 20). From an intercultural perspective, the exercise could have been used to encourage students to critically engage with the text and analyze their perceptions about youth identity vis-à-vis claims made in the text.

\section{Look at the mind-map below and describe youth from Iqbal's perspective.}

representative of the nation

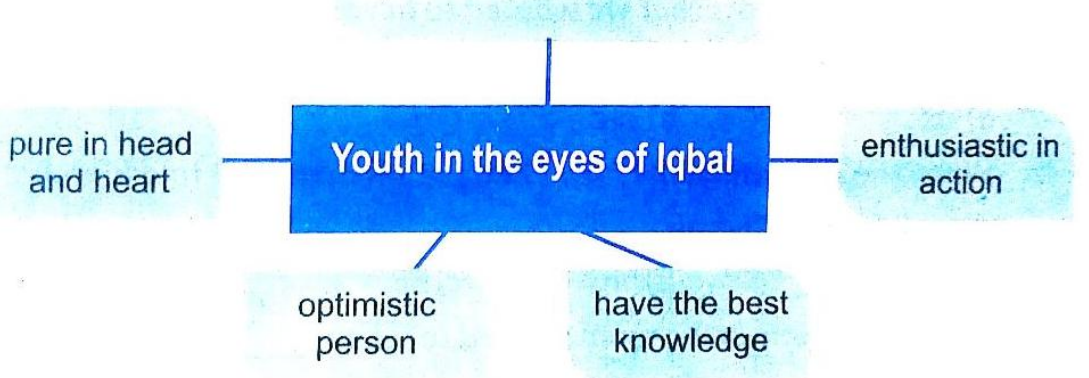

Figure 2: Sample exercise diagram for students from the textbook

\section{Otherization}

Otherization is underpinned by strong prejudices, preconceptions, and dominant discourses that stereotype individuals as group members having homogenous and static group characteristics. Otherization is appealing because it renders complexity redundant and it does not seek a deeper understanding of its object. "The Two Bargains" (pp. 64-74) narrates two short narratives from the time of the prophet Muhammad in which two of his wealthy companions show extraordinary generosity and help poor people in Medina (Saudi Arabia) to have free drinking water and food supply. While the second of these short narratives focus on the interaction between the Muslim companions of the prophet, the first narrative also involves a Jew who owns a well charging exorbitant prices for water. After the prophet's companion bargains with him and secures the right to use the well every alternate day when Muslims could get free water from the well, the Jew runs out of business as no one would come for water on the day when he would charge them. He had to go to the prophet's companion and sell the rest of his ownership of the well. This way, the text declares, the Jew "learned a bitter lesson".

The narrative is based on factual historical events. Stated themes of the text are "justice" and "generosity" - justice for the Jew as he was greedy and lost his business and exemplification of the generosity of companions of the prophet. Generosity is a good subject for illustrating to young learners to inculcate among them ideas of selflessness and philanthropy. On the other hand, the narrative is ideologically slanted towards stereotyping the only Other in the narrative (the Jew) as stereotypically representing the rest of individuals from the same religious group. Although the text does not state this overtly, it exposes young learners to a monolithic stereotype of the Other that might as well influence their future interaction with perceived others in real-life situations.

One would expect that exercise and group activities given after the text would encourage learners to bracket their responses and evaluate critically their beliefs about characters in the text and analyze their attitudes vis-à-vis the characters. However, it does not focus on such activities. Bracketing is an important tool to see complexity beyond stereotypes. It refers to "putting aside simplistic notions about what is 'real' or 'unreal' in your perception of 'another culture" and plays a key role in the analysis of one's subjectivity (Liu, 2020). Overgeneralizing from individual examples occurs when we stop seeking complexity, do not seek and appreciate complexity, and take for granted reinforcement of our preconceptions. Exercise activities based on this text, however, include comprehension-based questions, a writing summary, and three pages of discrete grammar exercises. The expected learning outcomes of the text state: "After reading the unit, students will be able to apply critical thinking to interact with the text and use 
intensive reading strategies" (p. 64). One focus group activity where students could have engaged in a meaningful analysis of real-life situations around the themes of "justice" and "generosity" is titled "Listening and speaking". However, this section only seeks students' opinions about economic inequality: "Work in pairs and express your personal ideas/ feelings/ emotions on economic inequality in society and how it can be minimized. Share your views in front of the class" (p. 72).

The text projects a monolithic image of the Other and does not encourage students to reflexively analyze their perceptions, responses, beliefs, and attitudes towards in-group and out-group characters represented in the text. Young impressionable learners are not encouraged to seek inwards, bracket their responses to stereotypes, and seek more information to understand the complexity of the Other.

\section{CONCLUSION}

The above analysis suggests that textbooks can play a key role in promoting intercultural understanding provided cultural awareness is taught explicitly as part of teaching a new language. Schools are powerful socio-political institutions that play a significant role in students' socialization into particular individuals with particular kinds of identities. This study started with the aim to analyze how the textual construction of students' identity informs notions of in-group and out-group perceptions of Self in the focal texts. Textual data analysis shows that the Class 10 English language textbook constructs a strong unitary national and religious identity but fails to involve students in a critical dialogic engagement with ideas expressed in the text. Students are served specific aspects of an ideal identity instead of inviting them to co-construct individual identities through group work and interaction with the teacher.

The second research question this study sought to explore related to how texts represent the Other and what role otherization may play in informing students' perception of the Self and their present and future trajectories of intercultural competence. The focal texts in this article did not seem to fare too well on this aspect of intercultural awareness and communication. Unless students are encouraged to bracket their self-perception of the Other based on previous experiences and socially circulating stereotypes critical intercultural awareness cannot be achieved. Similarly, teachers' capacity development is important so that they can encourage critical discussion in the classroom and promote the use of language learning as a tool for intercultural awareness.

To promote intercultural harmony and prepare learners for intercultural interactions, textbooks must model inclusive identities and promote questioning of stereotypical group identities (Khan et al., 2021a). Data analysis in the current article shows that texts included in the textbook promote strong in-group identities. Exercises and activities for students focus on lexico-syntactical aspects of the texts. The communicative and intercultural skills of the students are not stimulated in the textbook. To create a more stable world in this age of interconnectedness, mobility, and globalization, our young generation needs to develop fluid identities that are open to dialogue with the Other and seek complexity instead of simplification and stereotyping in intercultural encounters.

\section{LIMITATION AND STUDY FORWARD}

English language textbooks and classrooms need to move beyond traditional language teaching and incorporate active critical thinking and intercultural awareness to suit the needs of the students in the globalized world of our present times. A cultural focus on intercultural competence has communicative ends but there are further important advantages: It may not only encourage the development of identity but also encourage the awareness of others' identities and an element of stabilization in a world of rapid change. To create a more stable world in this age of interconnectedness, mobility, and globalization, our young generation needs to develop fluid identities that are open to dialogue with the Other and seek complexity instead of simplification and stereotyping in intercultural encounters.

\section{ACKNOWLEDGEMENT}

I am very sincerely thankful to all my co-authors, Rafique Ahmed Memon, Mansoor Khan, Sidra Amina, and Saood Khan who fully contribute to this research. I hope this research paper is beneficial to all potential researchers.

\section{AUTHORS CONTRIBUTION}

The introduction and literature review of this study was largely conceptualized by Imdad Ullah Khan and Rafique Ahmed Memon. Mansoor Khan has made a major contribution towards the conceptualization of the area of study, data collection from diverse sources, targeted public, discussions, and conclusions. The research concepts of the study and research methodology development and analyzed by Sidra Amina, and Saood Khan.

\section{REFERENCES}

1. Abe, M. (2020). Intercultural Competence of Elementary School Students in a Japanese EFL Context. JES Journal, 20(1), 68-83.

2. Ahmad, M., \& Shah, S. K. (2019). A critical discourse analysis of gender representations in the content of 5th grade English language textbook. International and Multidisciplinary Journal of Social Sciences, 8(1), 1-24. https://doi.org/10.17583/rimcis.2019.3989 
3. Ali, N., Ullah, A., Ali, R., Ali, N., \& Zeb, A. (2021). The curriculum of Khyber Pakhtunkhwa: An analysis of grade-IX English textbook with gender perspectives. Ilkogretim Online, 20(5).

4. Amin, R. U. (2021). Access to English, Schooling Background, and Habitus: Evidence from Pakistani Graduate Students. In Research on Teaching and Learning English in Under-Resourced Contexts (pp. 60-71). Routledge. https://doi.org/10.4324/9781003057284-5

5. Ariawan, S. (2020). Investigating Cultural Dimensions in EFL Textbook by Using Byram Checklist. Register Journal, 13(1), 123-152. https://doi.org/10.18326/rgt.v13i1.123-152

6. Arshad, A., Shah, S. K., \& Ahmad, M. (2020). Investigating cultural contents in English language teaching materials through textbook evaluation. Journal of Language and Cultural Education, 8(2), 127-145. https://doi.org/10.2478/jolace-2020-0017

7. Asadi, H., \& Sasani, F. (2017). Otherization in the foreign policy discourse of Mohammad Reza Pahlavi. ZABANPAZHUHI (Journal of Language Research), 9(22), 7-24.

8. Asif, T., Guangming, O., Haider, M. A., Colomer, J., \& Kayani, S. (2020). Moral education for sustainable development: Comparison of university teachers' perceptions in China and Pakistan. Sustainability, 12(7), 3014. https://doi.org/10.3390/su12073014

9. Aziz, F., Saleem, T., Saleem, A., \& Batool, R. (2020). From pragmatic competence to intercultural competence: Pakistani ESL teachers perspectives of teaching interculturality in ESL classroom. Amazonia Investiga, 9(33), 37-45. https://doi.org/10.34069/AI/2020.33.09.4

10. Baig, M. S., Javed, F., \& Siddiquah, A. (2020). Pakistani Students' Ethical and Social Development through Punjab Textbook Board (PTBB) Grade VIII English Textbook. Language in India, 20(7).

11. Darvin, R., \& Norton, B. (2015). Identity and a model of investment in applied linguistics. Annual Review of Applied Linguistics, 35, 36-56. https://doi.org/10.1017/S0267190514000191

12. Deswila, N., Kustati, M., Yusuf, Y. Q., \& Harun, R. N. S. R. (2021). Cultural Contents In The Elt Textbook Prepared By The Indonesian Ministry Of Education For Secondary Schools. Journal of Nusantara Studies (JONUS), 6(1), 222-241.

13. Dinh, T. N., \& Siregar, F. L. (2021). Intercultural Competence and Parsnip: Voices From Teachers of English in Australia. In Intercultural Competence Past, Present and Future (pp. 255-274). Springer, Singapore. https://doi.org/10.1007/978-981-15-8245-5 12

14. Flores, N., Kleyn, T., \& Menken, K. (2015). Looking holistically in a climate of partiality: Identities of students labeled long-term English language learners. Journal of Language, Identity \& Education, 14(2), 113-132. https://doi.org/10.1080/15348458.2015.1019787

15. Gholaminejad, R., \& Raeisi-Vanani, A. (2021). English language teaching in Iranian mainstream schools: Pedagogical, societal and government policy environments. Issues in Educational Research, 31(1), 111-129.

16. Hacker, N. L., \& Umpstead, R. R. (2020). Study abroad programs for intercultural competence, equity pedagogy, and social justice in US educational leadership students: An example from Ireland and Northern Ireland. Handbook on promoting social justice in education, 1021-1048. https://doi.org/10.1007/978-3-030$14625-2 \quad 121$

17. Holmes, P. (2015). Intercultural encounters as socially constructed experiences. The Routledge companion to cross-cultural management, 237.

18. Islam, K. M. M., \& Asadullah, M. N. (2018). Gender stereotypes and education: A comparative content analysis of Malaysian, Indonesian, Pakistani and Bangladeshi school textbooks. PloS one, 13(1), e0190807. https://doi.org/10.1371/journal.pone.0190807

19. Jackson, J. (2021). Building an online community to contest stereotyping and Otherization during study abroad. In Intercultural Competence Past, Present and Future (pp. 209-227). Springer, Singapore. https://doi.org/10.1007/978-981-15-8245-5 10

20. Joo, S. J., Chik, A., \& Djonov, E. (2020). The construal of English as a global language in Korean EFL textbooks for primary school children. Asian Englishes, 22(1), 68-84. https://doi.org/10.1080/1348 $\underline{8678.2019 .1627636}$

21. Khan, I. U., Imtiaz, A. Shahzad, A. S., Khan, S., \& Amina, S. (2021a). Emerging Academic Identities in a Foreign Context: Pakistani International Doctoral Students' Responses to Supervisory Feedback in New Zealand. Linguistica Antverpiensia, 21(1) 1481-1502

22. Khan, I. U., Perveen, A., \& Imtiaz, A. (2021b). Social Construction of Language Learners: A Bakhtinian Analysis of EFL Learners' Subjectivity in the Multilingual Context of Pakistan. Progressive Research Journal of Arts \& Humanities, 3(1), 22-35. https://doi.org/10.51872/prjah.vol3.Iss1.80

23. Khan, I. U., Rahman, G., \& Hamid, A. (2021). Poststructuralist Perspectives on Language and Identity: Implications for English Language Teaching Research in Pakistan. sjesr,4(1), 257-267. https://doi.org/10. 36902/sjesr-vol4-iss1-2021(257-267)

24. Liu, H. (2020). Voiceless Teachers in Education: Intercultural Experiences and Perceptions of Chinese Immigrant Teachers in Finland. Helsinki Studies in Education.

25. Mahboob, A. (2015). Identity management, language variation, and English language textbooks: Focus on Pakistan. Language and Identity Across Modes of Communication, 6, 153-177. https://doi.org/10.1515/97 $\underline{81614513599.153}$ 
26. Manzoor, H., Ahmed, A., \& Umrani, S. (2019). Intercultural communication at play in local english textbooks. Journal of Education and Social Sciences, 13(2). ISSN 2289-9855.

27. McDonough, G. P. (2018). The Joy of Dialogue in an intercultural world: Educational implications from Evangelii Gaudium. Annual Review of the Sociology of Religion, 222-244. https://doi.org/10.116 3/9789004380073 013

28. Mesaros, J. K. (2016). Utilizing analytical autoethnography to enhance educator intercultural competence (Doctoral dissertation, Eastern University).

29. Mukhtar, A. A., Sahito, Z., \& Siddiqui, A. (2021). Teachers' Perception about English as a Medium of Instructions: Evidence from the Government Higher Secondary Schools of Sindh, Pakistan. Theory and Practice in Language Studies, 11(4), 362-371. https://doi.org/10.17507/tpls.1104.05

30. Osman, H. (2015). Investigating English teachers' perceptions of intercultural communicative competence in the Kingdom of Saudi Arabia. University of San Francisco.

31. Peng, Z. N. (2020). From Textbooks to Teachers' Perspectives: Building Chinese Students' Intercultural Competence Through College English Teaching (Doctoral dissertation, Middle Tennessee State University).

32. Pérez Gracia, E. (2016). Implementation of the intercultural axis in CLIL-Primary Education: Assessment through teachers' planning and textbooks.

33. Riebeling, F. (2018). From Concept to Classroom: Theoretical and Practical Approaches and Gaps to Multicultural Education in Chile. Unpublished Education Studies capstone, Yale University, New Haven, CT.

34. Salem, L. R. (2019). The Cultural Content of English Language Textbooks: The Target, the Local, or the Third Place Culture. Edited by: Wafa Zoghbor, Suhair Al Alami, \& Thomaï Alexiou, 241.

35. Sarmiento, I., Zuluaga, G., Paredes-Solís, S., Chomat, A. M., Loutfi, D., Cockcroft, A., \& Andersson, N. (2020). Bridging Western and Indigenous knowledge through intercultural dialogue: lessons from participatory research in Mexico. BMJ Global Health, 5(9), e002488. https://doi.org/10.1136/bmjgh-2020-002488

36. Setyono, B. (2018). The portrayal of women in nationally-endorsed English as a foreign language (EFL) textbooks for senior high school students in Indonesia. Sexuality \& culture, 22(4), 1077-1093. https://doi.org/10.1007/s12119-018-9526-2

37. Setyono, B., \& Widodo, H. P. (2019). The representation of multicultural values in the Indonesian Ministry of Education and Culture-Endorsed EFL textbook: a critical discourse analysis. Intercultural Education, 30(4), 383-397. https://doi.org/10.1080/14675986.2019.1548102

38. Tong, Z. (2020). Implementing the Rabat Commitment: The Development of Intercultural Communicative Competence (ICC) as a Pedagogical Framework in a Chinese Educational Context.

39. Zhang, J. (2021). Imagined communities and identity options in Beijing Olympic English textbooks. In Language Policy and Planning for the Modern Olympic Games (pp. 144-166). De Gruyter Mouton. https://doi.org/10.1515/9781614514954-006 